This post print has been published in:

Applied Thermal Engineering, Volume 53, Issue 1, 29 April 2013, Pages 49-56

DOI: 10.1016/j.applthermaleng.2013.01.004

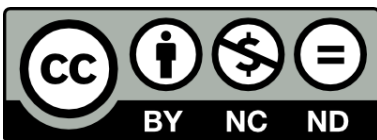

\title{
An Experimental Heat-Transfer Study for a Heat-Recovery Unit Made of Corrugated Tubes
}

\author{
Primož Poredoš, Tomaž Šuklje, Sašo Medved, Ciril Arkar* \\ University of Ljubljana, Faculty of Mechanical Engineering, Askerceva 6, 1000 Ljubljana, Slovenia, \\ *corresponding author \\ Tel: + 3861 4771234, fax: +38612518567, e-mail: ciril.arkar@fs.uni-lj.si
}

\begin{abstract}
This paper presents a study of the thermal characteristics of a concentric-tube heat exchanger that is a key element in local ventilation device. The inner tube of the concentric-tube heat exchanger has a sinusoidal, wavy surface in the longitudinal direction, which enables heat transfer enhancement. The tube can be stretched to a certain extent and thus change the corrugation of the heat-transfer surface area. We designed an experiment in which we used the Wilson-plot method to separately determine the convective heat-transfer coefficient on the inside and outside of the inner tube of the concentrictube heat exchanger with different corrugation ratios. Based on the measurements correlation equations were developed to calculate the convective heat-transfer coefficient for any corrugation ratio, which allows us to simplify the design of local ventilation devices. Performed studies showed that, compared to a smooth tube, the convective heat-transfer coefficient increased only in the case of corrugated tubes with a corrugation ratio of less than 1.648, but the heat transfer was more intense for all considered corrugated tubes by $65 \%$ to $90 \%$ due to the increased heat-transfer surface area. The highest heat transfer rate was observed for the case of the maximum-stretched tube with a corrugation ratio of 1.401 , which is advantageous also in terms of material consumption.
\end{abstract}

\section{Keywords:}

Convective heat-transfer coefficient

Corrugated tubes

Wilson-plot method

Heat Exchanger 


\section{Nomenclature}

A tube heat-transfer surface area $\left(\mathrm{m}^{2}\right)$

C constants used in the Wilson-plot method

$\mathrm{C}$ constant in equation for $\mathrm{Nu}$ number

$\mathrm{c}_{\mathrm{p}} \quad$ specific heat capacity $(\mathrm{J} / \mathrm{kg} \mathrm{K})$

$\mathrm{d}$ tube diameter (m)

$\mathrm{k}$ coverage factor of expanded uncertainty

$\mathrm{L} \quad$ length of the heat exchanger (m)

$\dot{m} \quad$ mass flow rate $(\mathrm{kg} / \mathrm{s})$

$\mathrm{R}$ thermal resistance $(\mathrm{K} / \mathrm{W})$

$\mathrm{T}$ temperature $(\mathrm{K})$

$\mathrm{V}_{\mathrm{r}} \quad$ reduced velocity

LMTD logarithmic mean-temperature difference (K)

\section{Greek letters - Symbols}

$\alpha \quad$ convective heat-transfer coefficient $\left(\mathrm{W} / \mathrm{m}^{2} \mathrm{~K}\right)$

$\phi \quad$ corrugation ratio

\section{Dimensionless groups}

$\mathrm{Nu} \quad$ Nusselt number

Pr Prandtl number

Re Reynolds number

\section{Subscripts}

$\begin{array}{ll}\text { i } & \text { inner } \\ \text { in } & \text { inlet } \\ \text { o } & \text { outer } \\ \text { out } & \text { outlet } \\ \text { ov } & \text { overall } \\ \mathrm{p} & \text { smooth tube } \\ \text { w } & \text { tube wall }\end{array}$

\section{Superscripts}

m exponent of Pr number

$\mathrm{n}$ exponent of reduced velocity or Re number 


\section{Introduction}

An acceptable level of working and living conditions and a desire for the utmost comfortable living conditions require increasing energy use for heating, ventilation and cooling, which is in contrast to many priorities and EU efforts to reduce energy use in buildings and thus reduce greenhouse-gas emissions. Reduced energy use in buildings can be provided through new, energy-efficient buildings and the renovation of old buildings, as well as introduction of energy-efficient building-utility systems and a greater use of renewable and natural energy sources.

Appropriate air quality in buildings can be provided by energy efficient mechanical ventilation systems. In the case of building renovation or in the case of different requirements for the ventilation of different parts of buildings it turns out that local ventilation systems may be more energy efficient [1]. Therefore, we designed a local ventilation device that allows heat transfer between exhaust air and fresh outside air and can be integrated into the building envelope and connected with elements on the building envelope for exploiting renewable energy sources. The central element of this mechanical ventilation device is a concentric-tube heat exchanger that is made of a corrugated tube surface.

The heat transfer in concentric-tube heat exchangers that are made of smooth tubes is well understood $[2,3]$. The heat transfer could be increased by increasing the convective heat-transfer coefficient and/or by increasing the heat-transfer surface area. This is often achieved by adding fins on the inner tube. The influence of longitudinal, rectangular fins on the heat transfer and the pressure drop was studied by Braga and Saboya [4]. A heat transfer fluid in the inner tube of the concentric-tube heat exchanger was water and in outer isolated tube was air. They found that the Nusselt number of the finned section was lower than in the case of the smooth tube, but the heat-transfer surface area was significantly greater. They suggested that the presence of the fins between the tubes reduces the intensity of the turbulent mixing and consequently reduces the average convective heat-transfer coefficient. The pressure drop in the case of finned tubes is larger than in the case of smooth tubes. A similar experiment, but with wavy fins, was designed by $\mathrm{Yu}$ and Tao [5]. In both tubes the heat transfer fluid was air. The measurements were carried out for tubes with 4, 8, 12, 16 and 20 fins. They found that the fins have a major influence on heat transfer, since the intensity of the heat transfer increases with the number of fins. A tube with 20 fins has an up to 12 times more intense heat transfer with the same mass flow and it is up to 2 times more intense for the same pumping power. Çakmak et al. [6] achieved increased heat-transfer surface area in a concentric-tube heat exchanger by using the inner tube that is sine-shaped in the radial direction. Two heat exchanger configurations were tested, the first one with the wave amplitude of $4 \mathrm{~mm}$ and the distance between the peaks of $12 \mathrm{~mm}$ and the second one with the wave amplitude of $6 \mathrm{~mm}$ and the distance between the peaks of $20 \mathrm{~mm}$. Measurements were carried out for counter-flow heat exchanger in the range of Reynolds numbers between 2700 and 8800 that is mainly in the transition flow regime. By using the Wilson-plot method they found out up to $113 \%$ increase in the Nusselt number compared to a smooth, straight tube in aforementioned range of Reynolds numbers in the configuration with the wave amplitude of $4 \mathrm{~mm}$. The friction factor is increased by $81 \%$.

Enhancement by increasing the convective heat-transfer coefficient was investigated by Eiamsa and Promvonge [7]; they looked at a circular tube with corrugated walls and a circular tube with an inserted turbulator. They found a 3.0-4.2 times increase in the Nusselt number compared to a smooth, straight tube in the range of Reynolds numbers between 3000 and 9200 .

Usually, an increase in the heat transfer involves both an increased heat-transfer surface area as well as increased heat convection due to changed flow conditions (surface roughness, swirl flow, etc.).

Moawed et al. [8] used a smooth, sine-shaped inner tube in a concentric-tube heat exchanger. They analyzed the effect of the wavelength and the amplitude on the heat transfer and found an up to $93 \%$ increase in the heat transfer and an up to $130 \%$ higher friction factor compared to the smooth tube. For each type of tube they formed a correlation equation for the Nusselt number. A similar experiment was conceived by Yang and Chiang [9]. The convective heat-transfer coefficients were determined using the Wilson-plot method. They found that the heat transfer in such a configuration of heat exchanger is increased by $100 \%$, while the friction factor is increased by less than $40 \%$. 
Ramahlingam and Raghavan [10] used a "star-shaped" profile tube for the inner tube, which was additionally spirally twisted to induce a swirl flow. The heat convection inside the tubes was evaluated using the Wilson-plot method and they set a criterion equation for the friction factor and the Nusselt number. Tiruselvam et al. [11] expanded their research of EXTEK spirally twisted tube [10] to a laminar and transition flow regime. They also investigated a copper Turbo-C tube, which had an extension height approximately 5 times less compared to the EXTEK tube. The heat transfer coefficient was determined using the Wilson-plot method in laminar and turbulent flow regime. They found out that outer and inner side of EXTEK tube have the best and the worst heat transfer to pressure drop ratio compared to a smooth, straight tube and Turbo-C tube. Advantage of EXTEK tube is its compactness, high heat transfer enhancement, low weight and low cost. A tube with spiral longitudinal ribs was also used by Zdaniuk and Chamra [12]. In this case the convective heat-transfer coefficients and the friction factors were determined for eight tubes using the Wilson-plot method and compared with values for a smooth tube. They found that the values of the friction factor and the Nusselt number for all eight tubes with a fin area are larger than in case of a smooth tube for the entire range of Reynolds numbers. The increase of the heat transfer of the shell and tube heat exchanger in which instead of smooth, straight tube the twisted oval tubes were used, was studied by Tan et al. [13]. The first experiment, in which they studied the heat transfer and friction factor on the inside of the twisted oval tube, was conducted on concentric-tube heat exchanger. They found a $21 \%-31 \%$ increase in the heat transfer coefficient, compared to a smooth tube. Garcia et al. [14] analyzed the thermal-hydraulic properties of three tubes with different types of increased heat-transfer surface area which are mainly perpendicularly oriented to the fluid flow: corrugated tube, dimpled tube and tube with inserted wire coils. The results show that the shape of increased heat-transfer surface area affects pressure drop more than heat transfer increase. They also found out that the shape of increased heattransfer surface area has strong influence on transition from laminar to turbulent flow regime and that the turbulent flow regime occurs at lower Reynolds numbers than in a smooth tube.

A review of the literature shows that the heat transfer in concentric-tube heat exchangers can be significantly increased by increasing the heat-transfer surface area and an "agitated" flow regime. However, when reviewing the literature we did not find researches with tubes of a similar shape to that which we used when designing our local ventilation device. In an effort to establish the thermal characteristics of the local ventilation device, we also designed an experiment in which we separately determined the average convective heat-transfer coefficient on the inner and outer sides of the inner tube of the heat-exchanger tubes with different corrugation ratios. All the values were compared with the average convective heat-transfer coefficients for a smooth tube, calculated from equations that are available in the literature. Many studies of heat transfer in concentric-tube heat exchangers [6, 9-12] were performed using the Wilson-plot method. This method, which we also used in our research, is presented below.

\section{The Wilson-plot method}

The convective heat-transfer coefficient for a given heat-exchanger geometry and flow conditions can be determined experimentally by measuring the heat-transfer surface temperature and the fluid temperature. Based on these data the convective heat-transfer coefficient can be determined with the help of Newton's law of cooling, the basics of which are described in [3]. The main limitation of this methodology is the heat-transfer surface-temperature measurements, since the temperature varies along the length of the heat exchanger and often the heat-transfer surface is not accessible for measurements. In addition, temperature sensors can also significantly influence the fluid flow regime. For this reason, alternative methods are required for a determination of the convective heat transfer in heat exchangers.

One such method is the Wilson-plot method. It was developed in 1915 for the purpose of evaluating the convective heat-transfer coefficient in condensers of the "shell and tube" type [15]. The basis of this method is a separation of the total thermal resistance of the heat transfer in the internal thermal 
resistance (which determines the convective heat-transfer coefficient) and the residual heat resistance. The total thermal resistance $R_{o v}$ is expressed as a sum of three thermal resistances, based on the heat transfer inside the tube, $R_{i}$ the heat conduction through the tube wall $R_{w}$ and the heat transfer on the outside of the tube $R_{o}$ :

$$
R_{o v}=R_{i}+R_{w}+R_{o}
$$

Wilson [16] assumed that in the case of condensation, any variation in the total thermal resistance is only due to a variation of the convective heat-transfer coefficient inside the tubes, and the other heat resistance remains constant:

$$
R_{w}+R_{o}=C_{1}
$$

He also noted that the convective heat-transfer coefficient is proportional to an exponential function of the reduced velocity $v_{r}$ in the case of fully developed turbulent fluid flow inside the circular tubes:

$$
\alpha_{i}=C_{2} \cdot v_{r}^{n}
$$

Reduced velocity considers property variations of the fluid and the tube diameter and is today known as the Reynolds number. Considering equations (1), (2) and (3) it follows that the total thermal resistance is a linear function of $1 / v_{r}^{n}$, as shown in Fig. 1:

$$
R_{o v}=\frac{1}{C_{2} \cdot A_{i}} \cdot \frac{1}{v_{r}^{n}}+C_{1}
$$

The Wilson-plot method has the advantage that the convective heat-transfer coefficient is determined solely on the basis of measurements of the inlet and outlet temperatures and fluid flows. For each measurement the total thermal resistance can be determined as:

$$
R_{o v}=\frac{L M T D}{\dot{m}_{i} \cdot c_{p, i} \cdot\left(T_{i, \text { in }}-T_{i, \text { out }}\right)}
$$

After determining the constants $C_{1}$ and $C_{2}$ the internal and external convective heat-transfer coefficient can be determined from equations (3) and (6):

$$
\alpha_{o}=\frac{1}{\left(C_{1}-R_{w}\right) \cdot A_{o}}
$$

These equations represent the original Wilson-plot method. The Wilson-plot method was upgraded [15] using, instead of the reduced velocity $v_{r}$, the Reynolds number Re. This substitution represents one of the early modifications of the original method. Usage of the Wilson-plot method was also extended to heat exchangers with single-phase fluid flow [15]. It is important that during measurements, while changing the flow rate on one side of the tube, the thermal resistance on the other side is held constant by keeping the average fluid temperature, flow-rate and thus Re number to constant value. The method allows an easy determination of the constant $C$ in equation (7) in the case of using empirical, dimensionless correlations, for example, the Dittus-Boelter form equation:

$$
N u=C \cdot \operatorname{Re}^{n} \cdot \operatorname{Pr}^{m}
$$

However, it is necessary to assume a specific default value for the exponent of the Reynolds and Prandtl numbers. This shortcoming was eliminated by Briggs and Young [17]. Using a mathematical operation of the natural logarithm of $\operatorname{Re}^{n}$ and $1 /\left(R_{o v}-C_{1}\right)$ we get a new, linear dependence. The slope of the line represents the exponent of the Reynolds number, obtained by an iterative procedure. A modified Wilson-plot method, which accounts for the Reynolds number and iterative procedure proposed by Briggs and Young, was used to obtain heat transfer coefficients and Nusselt number correlation equations from experimental results of concentric-tube heat exchanger made of corrugated tubes. 


\section{Design of an air-to-air concentric-tube heat exchanger}

The basic element of our device, designed for local ventilation, is an insulated concentric-tube heat exchanger, as shown in Fig. 2. The outer tube of the counter-flow heat exchanger has a diameter of $d_{o}$ $=130 \mathrm{~mm}$ and inner tube $d_{i}=85 \mathrm{~mm}$. The ratio of the diameters in this case is 0.654 .

Both heat-exchanger tubes are manufactured from aluminium strip of thickness $0.1 \mathrm{~mm}$ that is rolled and connected with air-tight overlay joint. After that helical corrugation is formed to make it partly flexible tube with a longitudinal, sinusoidal, wave-shaped, heat-transfer surface. This means that the tube has an increased heat-transfer surface in comparison with a smooth tube. The wave height is 3 $\mathrm{mm}$, and the width of the aluminium strip when fully stretched is $58 \mathrm{~mm}$, taking into account part of the overlay joint. The tube-segment width of the manufactured tube is $14.67 \mathrm{~mm}$. The relationship between the surface area of the corrugated and the smooth, straight tube is defined by the corrugation ratio $\phi$, which is:

$$
\phi=\frac{A_{i}}{A_{p}}
$$

The corrugation ratio of the basic tube, which also represents the most compact design (i.e., length) of tube, is 3.955. The tube can be stretched to a certain extent, reducing the corrugation ratio, and consequently increasing the length of the heat exchanger or reducing material consumption for the same length. Fig. 3 shows examples of three different levels of corrugation ratio for the inner-tube of the heat exchanger used in the experiment.

We assumed that the compact design of the tube, with high-density waves, does not provide the optimum heat transfer, although this case has the largest heat-transfer surface area. Therefore, we designed an experiment in which we used the Wilson-plot method to determine the convective heattransfer coefficients on the inner and outer sides of the inner tube for different corrugation ratios.

\section{Experimental setup}

The experimental setup is shown schematically in Fig. 4. Both heat-exchanger tubes are inserted into square blocks made of thermal insulation material, which can be seen in Fig. 2. The minimum thickness of this thermal insulation material is $150 \mathrm{~mm}$. The length $\mathrm{L}$ of the heat exchanger in all measurements was $3.52 \mathrm{~m}$. The inner tube was supported along its length with 5 wire triangular supports to ensure the concentric shape of the heat exchanger.

The air temperature was measured at the inlet and the outlet of the heat exchanger. At each measurement point four thermocouples of the type $\mathrm{T}$ : $\mathrm{Cu}-\mathrm{CuNi}$ were used, which were previously calibrated in a thermostatically controlled bath. The expanded uncertainty $(\mathrm{k}=2)$ of the temperature measurement was $\pm 0.5^{\circ} \mathrm{C}$. All uncertainties are reported for the coverage factor $\mathrm{k}=2$ which corresponds to a coverage probability of approximately $95 \%$. The arrangement of the thermocouples over the cross-section of the channel and the mixing chamber before the thermocouples was in accordance with the recommendations of the ASHRAE standards 84 and $41.1[18,19]$.

The air flow-rate was measured with a volume flow meter, which was installed before the heating unit. The volume flow meter operates on the principle of the damping method and is adjusted to our experimental setup. The volume flow meter was calibrated with a laboratory sharp-edged orifice in the flow range that appears in the measurements. The expanded uncertainty of the air volume flow-rate measurements was $\pm 10 \%$.

The air temperature and steady state conditions were maintained with PID controllers connected to electric heating units with rated powers of $400 \mathrm{~W}$ and $2000 \mathrm{~W}$. The parts of the experimental setup, 
from the heating unit to the heat exchanger, were additionally insulated with $5 \mathrm{~cm}$ of thermal insulation.

In addition to the temperature and the flow rate, also the pressure drop across both air flows of the heat exchanger was measured. The expanded uncertainty of the pressure-drop measurements was $\pm 1 \%$ of the measurement range.

The measurements were performed for 7 different corrugation ratios $\phi$ of the inner tube. This was achieved by regular stretching and shortening of the tube, while at the same time the length of the heat exchanger was maintained constant. The characteristics of each tube are shown in Table 1.

\section{Experimental results}

The average convective heat-transfer coefficients on the inside $\left(\alpha_{i}\right)$ and outside $\left(\alpha_{0}\right)$ of the inner tube of the heat exchanger were determined using the Wilson-plot method for each of the seven corrugation ratios of the inner tube. For all the measurements the warmer air flow was in the tube, which is the expected operation mode of the local ventilation device. The air-flow range was slightly wider than the intended range of air-flow during the operation of the device, which is from 40 to $80 \mathrm{~m}^{3} / \mathrm{h}$. For every corrugation ratio of the tube two series of measurements at different constant air flow-rates and different LMTD were carried out. In each series of measurements air-flow rates were varied on one side, while the air flow-rate and the mean temperature of the other side were held constant.

Based on the measured values for each series a Wilson-plot-method graph that shows a plot of the thermal resistance as a function of the inverse value of the Reynolds number was obtained. Fig. 5 shows the measurement results for the tubes with $\phi=3.955$. The result of the calculation is the exponent $\mathrm{n}$ of the Reynolds number, obtained with the iterative procedure presented in Section 2. Based on this the convective heat-transfer coefficient for a given air flow-rate or Reynolds number was calculated using Eq. 3 and 6 (with Re instead of $v_{r}$ ). The expanded uncertainties of calculated values are for the Reynolds number $\pm 11 \%$ and for the convective heat transfer coefficient and Nusselt number $\pm 14 \%$.

For each corrugation ratio of the inner tube dimensionless correlation equations for the Nusselt number was developed in the form of the Dittus-Boelter equation for a smooth tube (equation 7). An exponent of the Prandtl number equal to 0.3 for flow in the tube (cooling) and 0.4 for the flow in the annulus (heating) was assumed. The constant $\mathrm{C}$ was determined by the method of least squares, taking into account all the measurements made for each corrugation ratio. The results are shown in Tables 2 and 3, where also the range of Reynolds numbers used in the experiment is shown.

The exponents of the Reynolds number that were obtained from the measurement results for all 7 tubes with different corrugation ratios are in range from 0.944 to 0.981 , mainly due to the fact that most of the measurements were made in the transition region and not in the turbulent region. The exponent $\mathrm{n}$ values are also consistent with the measurements of the pressure drop where the exponent of the Reynolds number in the equation for the friction factor is about 1 less than the exponent $n$ shown in Table 2 and 3. This is also consistent with the results of other studies $[5,7,10]$.

Fig. 6 shows a comparison of the Nusselt number for the measured results and results calculated with the correlation equation (Table 2 and 3). For a more representative picture the ratio of the Nusselt numbers between the tubes is lower by 0.5 . The correlation equations describe all the experimental values of the Nusselt numbers that were obtained within $\pm 4.9 \%$ in the tube and $\pm 5.2 \%$ in the annulus.

Fig. 7 and 8 show the dependence of the Nusselt number on the Reynolds number for the flow in the tubes and between the tubes for all 7 levels of corrugation. For comparison, on the charts there are also the values of the Nusselt numbers for a straight, smooth tube, with the values calculated by the equations from Heat Atlas [2] for turbulent flow. For the transition region it is assumed to linearly decrease towards the value of the Nusselt number for laminar flow, as proposed in [2]. 
From the results it can be concluded that the intensity of the heat transfer increases with a decreasing corrugation ratio of the tubes, and that in comparison with a straight, smooth tube the heat transfer is higher for only two minimum corrugation ratios ( ${ }^{\phi}=1.648$ and 1.401). It can also be seen that in comparison with a smooth tube the heat transfer is better on the outside of the inner tube.

The effectiveness of the heat exchanger is, in addition to the convective heat-transfer coefficient of both air flows, also dependent on the heat-transfer surface area, which in our case is increased in comparison with the smooth tube. The influence of both parameters on an increase in the heat transfer can be shown if the measurement results are evaluated with regard to the heat-transfer surface of the smooth tube and not the actual heat-transfer surface of the corrugated tube. The results are shown in Fig. 9 and 10. It can be seen that in this case the Nusselt numbers are higher than in the case of smooth tubes for all the corrugated tubes. In comparison with the smooth tube the Nusselt numbers are higher by $55 \%$ to $85 \%$ for the flow inside the tube and by 60 to $90 \%$ for the flow between the tubes.

The results of pressure-drop measurements are presented in Fig. 11. Results showed that, in comparison with the smooth tube, the pressure drop is 2.9 to 3.4 times higher in the tube and 3.4 to 4.0 times higher between the tubes, and is the largest for the tube with smallest corrugation ratio.

In terms of designing and optimizing a heat exchanger's effectiveness in a device for local ventilation the use of separate equations for calculating the convective heat-transfer coefficient for each corrugation ratio is relatively impractical. Therefore, a unified, dimensionless, correlation equation for the Nusselt numbers that is valid for the entire range of the corrugation ratios of the inner tube was designed. Nonlinear fitting, based on the least square method, was used to determine correlation equations. The FindFit function in Mathematica software package [20] was used to determine the new constants $\mathrm{C}$ in Equation 7 with a potency dependence on the corrugation ratio and exponent for the Reynolds number. The equations for the calculation of the Nusselt numbers on the inside and outside of the inner tube are:

$$
\begin{aligned}
& N u_{i}=0.0093 \cdot \phi^{-1.117} \cdot \operatorname{Re}_{i}^{0.959} \cdot \operatorname{Pr}_{i}^{0.3} \\
& N u_{o}=0.0099 \cdot \phi^{-1.077} \cdot \operatorname{Re}_{o}^{0.968} \cdot \operatorname{Pr}_{o}^{0.4}
\end{aligned}
$$

Fig. 11 shows a comparison of the measured and calculated (with equations 9 and 10) values for the Nusselt numbers. The deviation of the Nusselt numbers for most of the data (more than $95 \%$ of the value) is within $\pm 6.5 \%$ for the tube and $\pm 9.0 \%$ for the annulus. This deviation is acceptable, since we estimate that with a real implementation of the heat exchanger it will be hard to ensure a uniform distension of the tube and a constant corrugation ratio along the length of the concentric-tube heat exchanger.

\section{Conclusions}

This paper presents a study of corrugated-tube heat transfer in a concentric-tube counter-flow heat exchanger. The tube has a sinusoidal wavy surface in the longitudinal direction and can be partially stretched, and thus the degree of corrugation can be changed. Due to the increased heat-transfer surface area and the intensive heat transfer, a corrugated tube, in comparison with a smooth tube, enables greater effectiveness or a more compact design of concentric-tube counter-flow heat exchanger.

The average convective heat-transfer coefficient on the inside and outside of the corrugated tube was determined using the modified Wilson-plot method. The measurements were performed for 7 different tubes, i.e., from the most compact form, the as-manufactured tube, to the most stretched form, which can be achieved by manually extending, without distorting the heat-transfer surface. In comparison 
with the smooth tube, the corrugated tube had a 1.401 to 3.955 times higher value of the heat-transfer surface area.

Based on measurements for every tube with a different corrugation ratio dimensionless equations were developed in Dittus-Boelter form to calculate the Nusselt number. The measurement results showed that in comparison with smooth tube the Nusselt number is higher only for tubes with a corrugation ratio of 1.648 and 1.401. However, the heat transfer due to the increased heat-transfer surface area compared with a smooth tube is more intense in all types of corrugated tubes.

By using corrugated tubes the heat transfer is increased by $65 \%$ to $90 \%$, with the most stretched tube, having a corrugation ratio of 1.401 , giving the best result. The pressure drop in corrugated tubes is 3 to 3.5 times higher than in smooth tubes.

For the design purpose of counter-flow, concentric-tube heat exchangers unified equations were formed to calculate the Nusselt number on the inner and outer side of the corrugated tube, which are valid for the corrugated tubes with corrugation ratios from 1.401 to 3.955 , with an inner tube diameter of $85 \mathrm{~mm}$ and an outer tube diameter of $130 \mathrm{~mm}$, and airflow range from 40 to $80 \mathrm{~m}^{3} / \mathrm{h}$.

\section{Literature}

[1] B. Mahler, R. Himmler, DeAL - Evaluation of building envelope integrated decentral ventilation systems: From the test stand XIII, xia Intelligente Architektur 63 (2008) 66-70. (in German)

[2] Verein Deutscher Ingenieure, VDI - Heat Atlas, Springer - Verlag, Berlin, Germany, 2006. (in German)

[3] F.P. Incropera, D.P. DeWitt, T.L. Bergman, A.S. Lavine, Fundamentals of heat and mass transfer, Wiley, Hoboken, USA, 2007.

[4] C.V.M. Braga, F.E.M. Saboya, Turbulent heat transfer, pressure drop and fin efficiency in annular regions with continuous longitudinal rectangular fins, Experimental Thermal and Fluid Science 20 (1999) 55-65.

[5] B. Yu, W.Q. Tao, Pressure drop and heat transfer characteristics of turbulent flow in annular tubes with internal wave-like longitudinal fins, Heat and Mass Transfer 40 (2004) 643-651.

[6] G. Çakmak, H. L. Yücel, Z. Argunhan, C. Yildiz, Experimental Investigation of Thermal performance in a Concentric-Tube Heat Exchanger with Wavy Inner Pipe, International Journal of Thermophysics 33 (2012) 1055-1067.

[7] S. Eiamsa-ard, P. Promvonge, Enhancement of Heat Transfer in a Circular Wavy-surfaced Tube with a Helical-tape Insert, International Energy Journal 8 (2007) 29-36.

[8] M.A. Moawed, E. Ibrahim, A. Gomaa, Thermal performance of a pipe in pipe heat exchanger with sinusoidal inner pipe, Energy Conversion and Management 49 (2008) 678-686.

[9] R. Yang, F.P. Chiang, An experimental heat transfer study for periodically varying-curvature curved-pipe, International Journal of Heat and Mass Transfer 45 (2002) 3199-3204.

[10] T. Ramahlingam, V.R. Raghavan, The Tube Side Heat Transfer Coefficient for Enhanced Double Tube by Wilson Plot Analysis, Journal of Applied Sciences 11 (2011) 1725-1732.

[11] R. Tiruselvam, W. M. Chin, V. R. Raghavan, Double tube heat exchanger with novel 
enhancement: part II - single phase convective heat transfer, Heat and Mass Transfer 48 (2012) 14511462.

[12] G.J. Zdaniuk, L.M. Chamra, P.J. Mago, Experimental determination of heat transfer and friction in helically-finned tubes, Experimental Thermal and Fluid Science 32 (2008) 761-775.

[13] X. Tan, D. Zhu, G. Zhou, L. Zeng, Heat transfer and pressure drop performance of twisted oval tube heat exchanger, Applied Thermal Engineering 50 (2013) 374-383.

[14] A. Garcia, J.P. Solano, P.G. Vicente, A. Viedma, The influence of artificial roughness shape on heat transfer enhancement: Corrugated tubes, dimpled tubes and wire coils, Applied Thermal Engineering 35 (2012) 196-201.

[15] J. Fernández-Seara, F.J. Uhía, J. Sieres, A. Campo, A general review of the Wilson plot method and its modifications to determine convection coefficients in heat exchange devices, Applied Thermal Engineering 27 (2007) 2745-2757.

[16] E.E. Wilson, A basic of rational design of heat transfer apparatus, ASME Journal of Heat Transfer 37 (1915) 47-70.

[17] D.E. Briggs, E.H. Young, Modified Wilson plot techniques for obtaining heat transfer correlations for shell and tube heat exchangers. Chemical Engineering Progress Symposium Series 65 (1969) 35-45.

[18] ASHRAE standard 84, Method of testing air-to-air heat/energy exchangers, ANSI/ASHRAE, Atlanta, USA, 2008.

[19] ASHRAE standard 41.1 (RA 2006), Standard method for temperature measurement, ANSI/ASHRAE, Atlanta, USA, 2006.

[20] Wolfram Research, Mathematica 8, Champaign, USA, 2012. 
Figure captions:

Fig. 1. Basic shape of the graph of the original Wilson-plot method [10]

Fig. 2. Design of local heat-recovery unit with counter-flow concentric-tube heat exchanger made of corrugated tubes; $d_{o}=130 \mathrm{~mm}, d_{i}=85 \mathrm{~mm}$.

Fig. 3. Example of three different corrugation ratios of the inner tube; (a) top $\phi=1.648$, middle $\phi=$ 2.472 , bottom $\phi=3.955$ (b) schematic diagram of a longitudinal section of tube (Not to Scale)

Fig. 4. Experimental setup; $\mathrm{L}=3.52 \mathrm{~m}, \mathrm{~d}_{\mathrm{o}}=130 \mathrm{~mm}, \mathrm{~d}_{\mathrm{i}}=85 \mathrm{~mm}$

Fig. 5. Graph of the Wilson-plot method for the tube and the annulus; tube with $\phi=3.955$

Fig. 6. The ratio of measured and calculated (Equation 7, Table 2 and 3) Nusselt numbers; the ratio for the annular side is lower by 0.5

Fig. 7. Plot of the Nusselt number versus the Reynolds number in the inner tube for 7 corrugated tubes and a smooth tube

Fig. 8. Plot of the Nusselt number versus the Reynolds number between tubes for 7 corrugated tubes and a smooth tube

Fig. 9. Plot of the Nusselt numbers versus the Reynolds number inside the tube; for all the corrugated tubes the heat-transfer surface area of smooth tubes $\left(A_{p}=0.934 \mathrm{~m}^{2}\right)$ was considered.

Fig. 10. Plot of the Nusselt numbers versus the Reynolds number between tubes; for all the corrugated tubes the heat-transfer surface area of smooth tubes $\left(\mathrm{A}_{\mathrm{p}}=0.934 \mathrm{~m}^{2}\right)$ was considered.

Fig. 11. Pressure drop versus the Reynolds number for flow in tube (solid line) and annulus (dashed line) for inner pipe with different corrugation ratios; calculated values for smooth tubes are shown with dotted line

Fig. 12. Comparison of the measured and calculated Nusselt numbers, with the calculated Nusselt numbers being calculated with the unified equations 
Tables:

Table 1: Corrugation ratios and heat-transfer surface areas of the inner-tube of heat exchanger.

\begin{tabular}{ccc}
\hline $\begin{array}{c}\text { Corrugation ratio } \\
\phi(-)\end{array}$ & $\begin{array}{c}\text { Heat-transfer surface area of } \\
\text { the tube with corrugated wall } \\
\mathrm{A}_{\mathrm{i}}\left(\mathrm{m}^{2}\right)\end{array}$ & $\begin{array}{c}\text { Length of tube in the case of } \\
\text { the fully stretched tube }(\mathrm{m})\end{array}$ \\
\hline 3.955 & 3.695 & 13.92 \\
3.64 & 3.233 & 12.18 \\
2.966 & 2.771 & 10.44 \\
2.472 & 2.309 & 8.70 \\
1.977 & 1.848 & 6.96 \\
1.648 & 1.540 & 5.80 \\
1.401 & 1.309 & 4.93
\end{tabular}

Table 2: Constants of the dimensionless correlation equation for flow in the tube and the range of equation validity

\begin{tabular}{ccccc}
\hline$\phi(-)$ & $\mathrm{C}(-)$ & $\mathrm{n}$ & $\mathrm{m}$ & $\mathrm{Re}$ \\
\hline 3.955 & 0.00204 & 0.961 & 0.3 & $7400-20900$ \\
3.64 & 0.00189 & 0.978 & 0.3 & $7500-21700$ \\
2.966 & 0.00210 & 0.981 & 0.3 & $7200-21100$ \\
2.472 & 0.00397 & 0.948 & 0.3 & $7700-20900$ \\
1.977 & 0.00396 & 0.969 & 0.3 & $7450-20500$ \\
1.648 & 0.00545 & 0.958 & 0.3 & $7900-20500$ \\
1.401 & 0.00660 & 0.957 & 0.3 & $7900-20000$
\end{tabular}

Table 3: Constants of the dimensionless correlation equation for the flow between the tubes and the range of equation validity

\begin{tabular}{ccccc}
\hline$\phi(-)$ & $\mathrm{C}(-)$ & $\mathrm{n}$ & $\mathrm{m}$ & $\mathrm{Re}$ \\
\hline 3.955 & 0.00242 & 0.959 & 0.4 & $3300-11500$ \\
3.64 & 0.00232 & 0.973 & 0.4 & $3500-10300$ \\
2.966 & 0.00273 & 0.980 & 0.4 & $3200-10600$ \\
2.472 & 0.00457 & 0.944 & 0.4 & $4000-10500$ \\
1.977 & 0.00487 & 0.970 & 0.4 & $3300-11100$ \\
1.648 & 0.00620 & 0.960 & 0.4 & $3500-10400$ \\
1.401 & 0.00763 & 0.955 & 0.4 & $3900-11000$
\end{tabular}

